\title{
Strategi berinovasi guru di sekolah menengah atas
}

\author{
M. Nur Mustafa ${ }^{*}$, Hermandra Hermandra, Zulhafizh Zulhafizh \\ Universitas Riau, Indonesia
}

\begin{tabular}{l} 
Article Info \\
\hline Article history: \\
Received Aug $08^{\text {th }}, 2021$ \\
Revised Sept $16^{\text {th }}, 2021$ \\
Accepted Oct $31^{\text {st }}, 2021$ \\
\hline
\end{tabular}

\section{Keyword:}

Strategi berinovasi guru Aktivitas inovatif Kreativitas guru

\begin{abstract}
ABSTRAK
Inovasi sebagai suatu terobosan yang dapat dilakukan guru dalam mendorong perbaikan pendidikan. Berbagai strategi dapat dilakukan guru dalam rangga menghadirkan inovasi. Inovasi yang dilakukan guru sebagai suatu yang perlu dideskripsikan. Maka, penelitian ini berupaya mendeskripsikan berbagai strategi guru yang mendorong aktivitas inovatif. Metode penelitian berupa survei dengan dilengkapi instrumen strategi berinovasi para guru Sekolah Menengah Atas di Kota Pekanbaru. Sampel guru sebagai informan berjumlah 108 orang diambil secara random. Instrumen yang digunakan dalam mengumpulkan data berupa angket berskala Likert. Analisis instrumen berkategori valid dengan berbagai varian kategori Alfa Cronbach's $(>0,400)$ dan Chi-kuadrat 20620,625 $(\mathrm{p}>0,05)$. Analisis data dilakukan melalui analisis korelasi Product Moment, deskriptif-mean dan standar deviasi, Anova satu arah, dan koefisien diterminan $(\mathrm{R})$ untuk mengindikasikan potensi pengaruh yang ditimbulkan masing-masing dimensi. Hasil penelitian mengungkapkan bahwa dimensi untuk berinovasi di sekolah menengah atas secara umum berkategori sangat tinggi $(4,722)$ pada SD 0,302. Hasil implementasi memperlihatkan dimensi penataan tugas tidak signifikan dalam strategi berinovasi baik antar kelompok maupun dalam kelompok. Ditinjau dari koefisien diterminan lebih rendah $(0,084)$ dibandingkan dimensi lain. Hal ini memperlihatkan strategi selain penataan tugas dapat menjadi pemicu dalam berinovasi di Sekolah Menengah Atas di Kota Pekanbaru.
\end{abstract}

(C) 2021 The Authors. Published by IICET.

This is an open access article under the CC BY-NC-SA license (https://creativecommons.org/licenses/by-nc-sa/4.0)

\section{Corresponding Author:}

M. Nur Mustafa,

Universitas Riau

Email: em_nur1388@yahoo.com

\section{Pendahuluan}

Kondisi saat ini memperlihatkan masih ada celah yang harus diperhatikan dalam upaya pelaksanaan pendidikan dan pengajaran di sekolah sebagaimana yang telah dicita-citakan dalam tujuan pendidikan (Prajana \& Astuti, 2020; Nurhadi, 2018). Pertama, nasib program wajib belajar 12 tahun, kedua, angka putus sekolah dari SMP ke jenjang SMA mengalami kenaikan dan ketiga, ketidaksesuaian antara dunia pendidikan dengan dunia kerja. Kondisi tersebut memaksa penyelenggara pendidikan, khususnya di sekolah-mengambil strategi atau langkah inovatif yang dapat menyelesaikan berbagai permasalahan yang ada, terutama dalam aspek pendidikan dan pengajaran. Langkah atau tindakan yang dilakukan dapat diinisiasi oleh guru dengan daya kreatifitasnya (Hapsari \& Fatimah, 2021; Susilo \& Sofiarini, 2020).

Melalui strategi yang direncanakan, para guru diharapkan dapat mendorong dalam mewujudkan harapan yang ada dalam dunia pendidikan yang terintegrasi di sekolah tempat bertugas, seperti mencerdaskan dan mengembangkan keterampilan peserta didik (Ulumdin \& Fujianita, 2019; Warnock \& Mohammadi-Aragh, 
2016). Langkah tersebut sebagai perwujudan dalam memperbaiki sistem pendidikan dan pengajaran yang ada. Untuk itu, sekolah dan berbagai unsurnya terutama guru dituntut untuk dapat berusaha mencapai kesuksesan dalam melaksanakan tugasnya sebagai pendidik. Guru diupayakan berkontribusi secara baik untuk bisa berinovasi melalui berbagai strategi yang dimiliki sehingga mampu memajukan sistem sekolah ditempat mereka bertugas (Suriansyah, 2015).

Tindakan guru di sekolah tidak hanya mengajar dan mengevaluasi tetapi berupaya menjaga kualitas prestasi peserta didik, secara luas kognitif, psikomotorik, dan afektif (Lubis, 2011). Pada tingkat sekolah menengah atas, ketika peserta didik siap secara kognitif, psikomotorik, dan afektif maka ini akan memberikan dampak pada kehidupannya. Apalagi pada tingkat sekolah menengah atas menjadi transisi peserta didik untuk masuk ke ranah sosial secara luas. Maka tindakan inovatif yang dilakukan guru dapat memaksimalkan peserta didik dalam mencapai tujuan belajar dan terlebih pada harapan atau keputusan hidup (Hapsari \& Fatimah, 2021; Ramsey \& Khan, 2021).

Berdasarkan alasan tersebut menjadi dasar dilakukan studi terkait dengan strategi berinovasi guru sekolah menengah atas Kota Pekanbaru dalam hal mewujudkan penyelenggaran pendidikan dan pengajaran di sekolah. Alasan dipilihnya tingkat sekolah menengah mengingat pada kondisi itu, peserta didik sudah mampu mengikuti guru dengan baik dalam penyelenggaraan pendidikan dan pengajaran bahkan turut membantu guru dalam mensukseskan tugasnya (Toropova et al, 2021; Rubie-Davies et al, 2015). Selain itu, hubungan antara guru dan peserta didik memainkan peran untuk melahirkan tindakan yang inovatif dan kreatif (Güçlü Yilmaz, 2021).

Pada dasarnya, berinovasi dalam penyelenggaraan pendidikan dan pengajaran merupakan upaya dalam memperbaiki aspek-aspek pendidikan dalam praktiknya. Untuk lebih jelasnya Moore et al (2018) inovasi adalah suatu perubahan yang baru, dan kualitatif berbeda dari hal (yang ada sebelumnya), serta sengaja diusahakan untuk meningkatkan kemampuan guna mencapai tujuan tertentu. Dalam kaitannya dengan dunia pendidikan di sekolah inovasi dapat diamati aspek, yaitu pembelajaran yang dilakukan, bereksprimen, dan berupaya merefleksikan terhadap hal-hal yang telah dilakukan (van der Rijst et al, 2019). Selain itu mampu membangun berbagai kebutuhan yang diperlukan (Jayalath et al, 2020) dan dikelompok sekolah menengah memiliki kebutuhan yang sangat tinggi dalam kegiatan pembelajaran sehingga diperlukan berbagai strategi.

Sebagai seorang guru di sekolah menengah, Mykhailyshyn et al (2018) mengingatkan harus bisa mendesain atau memikirkan strategi apa yang bisa membangun seseorang untuk berinovasi. Guru paham dulu prosedur dan pelaksanaan kegiatan di sekolah sehingga mampu membawa perubahan dalam berbagai aspek. Perubahan itu bisa dari aspek pedagogis, kegiatan ilmiah dan metodologis, maupun teknologi. Bahkan sangat diperlukan kemampuan dalam melakukan pengelolaan atau manajemen (Mykhailyshyn et al, 2018). Peserta didik, khususnya pada tingkat sekolah menengah yang sudah mampu bernalar kritis dan ilmiah melalui prosedur inovatif yang siapkan guru dapat membantunya dalam mengambil keputusan hidupnya, seperti bekerja atau lanjut studi (Ramsey \& Khan, 2021). Untuk itu diperlukan sebuah analisis terhadap berbagai persiapan yang akan dilakukan guru (Al-Imarah \& Shields, 2019).

Untuk melakukan berbaagai inovasi, guru dapat mengadopsi berbagai strategi yang bisa menjadi pilihan dalam membawa perkembangan sekolah ke arah yang lebih lebih baik. Ketika ada strategi yang didopsi seperti kurikulum, teknologi informasi, rekayasa, manajemen, maupun tugas, maka pastikan tindakan yang dirancang dan dilakukan nantinya memang memberikan sebuah terobosan dalam kehidupan sekolahpendidikan dan pengajaran (Lawrence \& Tar, 2018). Dalam kontek ini, seorang guru hendaknya memiliki pengetahuan dan wawasan yang baik sehingga langkah demi langkah untuk membawa perubahan dapat dirancang dan dilakukan. Rahmat (2020) ada tiga metode untuk berinovasi yang bisa dipikirkan oleh seorang guru, yaitu: insepsi, adaptasi, adopsi.

Di tingkat sekolah menengah atas, inovasi yang dilakukan guru berupaya mendorong minat dan kreatifivitas peserta didik dalam mencapai tujuan pembelajaran (Ekayanti et al, 2020; Pramayogi \& Hartanto, 2019). Revathi et al (2019) memberikan penjelasan bahwa selain mendorong aktivitas belajarnya, juga mempersiapkan peserta didik untuk bisa bekerja setelah selesai studi. Maka guru dapat memberikan berbagai stimulus yang tepat dan inovatif melalui upaya insepsi, adaptasi, bahkan mengadopsi sehingga peserta didik dapat memahami keadaan nyata atau menjalin kerja sama dengan pihak lain. Sithole et al (2016) menekankan agar guru memiliki rancangan dalam memenuhi kebutuhan peserta didik melalui pengalaman, meniru, atau melakukan penyesuaian dari yang ada. Hal ini mendorong mereka untuk improvisasi secara maksimal (Unal, 2017).

Nicholls (2018) menegaskan dalam menghadirkan inovasi atau pembaharuan, terlepas apakah gagasan itu datang dari bawah atau dari atas, yang penting adalah perlu memperhitungkan berbagai kendala yang 
akan dihadapi dan manfaat yang didapat ketika ide itu diterapkan. Sehubungan dengan itu maka sebelum upaya tindakan inovasi dilakukan, maka perlu disusun perencanaan yang matang tentang bagaimana mengatasi kendala itu, sehingga ide pembaharuan itu dapat dikembangkan, dijalankan, diatur, dan ditetapkan pada skala tertentu. De Smul et al (2018) sebagai seorang guru yang menjalankan tugasnya di sekolah menengah perlu melakukan analisis terhadap berbagai kemungkinan yang muncul terhadap inovasi tersebut. Guru dan berbagai sarana penunjang untuk menghadirkan berbagai strategi berinovasi perlu disinkronkan (Rahmad, 2020).

Beberapa ide yang dikembangkan dalam kegiatan pembelajaran ini memang bukan hal baru. Banyak guru yang melakukan kegiatan inovasi dalam pembelajaran berorientasi pada minat dan prestasi belajar (Mashuri et al., 2019; Hornstra et al, 2015; Lee, 2008), meningkatkan aktivitas belajar peserta didik dengan model pembelajaran yang telah didesain guru (Kii \& Dewa, 2020). Selain itu, beberapa penelitian juga mengamati guru dalam mempersiapkan sarana penunjang pembelajaran seperti bahan ajar dan media pembelajaran (Firmadani, 2020; Shalikhah, 2017; Zuriah et al, 2016). Bahkan, tindakan inovasi guru dalam meracang model pembelajaran dalam membantu siswa belajar sudah diamati (Bahri et al, 2021; Fadli et al, 2020; Astrawan, 2019). Pada penelitian ini mengamati pada aspek penguasaan informasi, membangun kepribadian, berpikir produktif, manajerial tugas, memberdayakan teknologi, realisasi kurikulum, pelaksanaan pembelajaran, rekayasa media, dan penataan tugas secara deskriptif dan korelasi. Penelitian ini memberikan ruang yang lebih luas dalam mengamati guru menjalankan tugasnya.

\section{Metode}

Metode penelitian ini berupa survei dengan dilengkapi instrumen strategi berinovasi para guru Sekolah Menengah Atas di Kota Pekanbaru Provinsi Riau yang terdiri SMAN 4, SMAN 12, SMKN 2, SMK Labor Binaan FKIP UNRI, MAN 1, dan MAN Model. Masing-masing sekolah diambil sampel 18 guru, secara keseluruhan sampel penelitian berjumlah 108 guru diambil secara random, terdiri dari $29(26,1 \%)$ laki-laki dan $78(73,9 \%)$ guru perempuan; 78 (72,2\%) guru berstatus sebagai PNS dan $30(27,8)$ bertatus non PNS dengan rentang usia 23 sampai 57 tahun. Pengumpulan data berdasarkan isian instrumen skala Likert.

Instrumen yang menjadi basis pengumpulan data berjumlah 60 pernyataan. Instrumen yang tidak valid tidak dijadikan sebagai analisis lanjutan. Hal mengingat hasil instrumen tidak valid tidak mampu mengukur apa yang mestinya diukur. Hasil akan bias apabila dilakukan analisis lanjutan (Bowden, Davey Smith, \& Burgess, 2015; Shardell \& Ferrucci, 2016). Ketidakvalidan ini dapat dipengaruhi oleh berbagai faktor yang beragam. Pernyataan yang hadir berpotensi tidak sentisitif terhadap faktor yang diukur (Swanson, 2019; Wang et al, 2018). Melalui analisis validitas diketahui pula nilai Alfa Cronbach's yang bervariasi tingkatannya. Alfa Cronbach's di bawah 0,400 tidak layak digunakan untuk pengumpulan data (Setiawan, 2020). Dari 60 pernyataan hanya 57 yang layak digunakan untuk pengumpulan data. Adapun proses analisis data dilakukan melalui analisis korelasi Product Moment, deskriptif-mean dan standar deviasi, Anova satu arah, dan koefisien diterminan (R) untuk mengindikasikan potensi pengaruh yang ditimbulkan masing-masing dimensi.

\section{Hasil dan Pembahasan}

\section{Deskripsi Strategi Berinovasi Guru}

Melalui analisis deskripsi strategi berinovasi para guru Sekolah Menengah Atas di Kota Pekanbaru Provinsi Riau diketahui mean 4,722 dan standar deviasi 0,302 dengan kategori sangat tinggi. Para guru memiliki harapan yang baik agar bisa menghadirkan berbagai inovasi dalam menjalankan profesinya. Gambaran tersebut dapat diamati di tabel 1.

Semua data di tabel 2 menunjukkan bahwa semua harapan dan hasrat para guru di semua aspek berkategori tinggi jika dilihat dari mean tanggapan yang diberikan. Reaksi tersebut dirincikan: mean 4,753 untuk penguasaan informasi pada standar deviasi 0,329 ; mean 4,725 untuk membangun kepribadian pada standar deviasi 0,295 ; mean 4,697 untuk berpikir produktif pada standar deviasi 0,371; mean 4,736 untuk manajerial tugas pada standar deviasi 0,315 ; mean 4,759 untuk memberdayakan teknologi pada standar deviasi 0,294; mean 4,726 untuk realisasi kurikulum pada standar deviasi 0,295; mean 4,722 untuk pelaksanaan pembelajaran pada standar deviasi 0,330; mean 4,706 untuk rekayasa media pada standar deviasi 0,240; dan mean 4,672 untuk penataan tugas pada standar deviasi 0,252. Dari sembilan dimensi ini, secara praktis para guru di lingkungan Sekolah Menengah Atas di Kota Pekanbaru Provinsi Riau telah mengimplementasikan semua dimensi. Namun demikian, dua dari sembilan dimensi tersebut, yaitu dimensi 
berpikir produktif dan dimensi penataan tugas lebih rendah dibandingkan dengan dimensi lainnya, walaupun secara klasikal berkategori sangat tinggi.

Tabel 1. Deskripsi Strategi Berinovasi Guru

\begin{tabular}{cllcl}
\hline No. & \multicolumn{1}{c}{ Dimensi } & Mean & SD & Kategori \\
\hline 1 & Penguasaan informasi & 4,753 & 0,329 & Sangat Tinggi \\
2 & Membangun kepribadian & 4,725 & 0,295 & Sangat Tinggi \\
3 & Berpikir produktif & 4,697 & 0,371 & Sangat Tinggi \\
4 & Manajerial tugas & 4,736 & 0,315 & Sangat Tinggi \\
5 & Memberdayakan teknologi & 4,759 & 0,294 & Sangat Tinggi \\
6 & Realisasi kurikulum & 4,726 & 0,295 & Sangat Tinggi \\
7 & Pelaksanaan pembelajaran & 4,722 & 0,330 & Sangat Tinggi \\
8 & Rekayasa media & 4,706 & 0,240 & Sangat Tinggi \\
9 & Penataan tugas & 4,672 & 0,252 & Sangat Tinggi \\
\hline & Mean & 4,722 & 0,302 & Sangat Tinggi \\
\hline
\end{tabular}

Semua data di tabel 2 menunjukkan bahwa semua harapan dan hasrat para guru di semua aspek berkategori tinggi jika dilihat dari mean tanggapan yang diberikan. Reaksi tersebut dirincikan: mean 4,753 untuk penguasaan informasi pada standar deviasi 0,329 ; mean 4,725 untuk membangun kepribadian pada standar deviasi 0,295; mean 4,697 untuk berpikir produktif pada standar deviasi 0,371; mean 4,736 untuk manajerial tugas pada standar deviasi 0,315 ; mean 4,759 untuk memberdayakan teknologi pada standar deviasi 0,294; mean 4,726 untuk realisasi kurikulum pada standar deviasi 0,295; mean 4,722 untuk pelaksanaan pembelajaran pada standar deviasi 0,330; mean 4,706 untuk rekayasa media pada standar deviasi 0,240; dan mean 4,672 untuk penataan tugas pada standar deviasi 0,252. Dari sembilan dimensi ini, secara praktis para guru di lingkungan Sekolah Menengah Atas di Kota Pekanbaru Provinsi Riau telah mengimplementasikan semua dimensi. Namun demikian, dua dari sembilan dimensi tersebut, yaitu dimensi berpikir produktif dan dimensi penataan tugas lebih rendah dibandingkan dengan dimensi lainnya, walaupun secara klasikal berkategori sangat tinggi.

Dimensi berpikir produktif merupakan proses pengembangan ide. Pada hakikatnya guru tidak hanya mengajarkan atau mentransfer informasi tetapi berupaya mendorong peserta didik untuk kritis dibawah bimbingan guru. Disini peran guru sangat diperlukan dalam menstimulus dan mengarahkan peserta didik. Keterampilan dan pengalaman yang dimiliki guru turut menentukan peserta didik berpikir kreatif dan kritis. Hamza \& Griffith (2006) guru harus bisa menciptakan lingkungan atau iklim belajar yang baik agar guru dan peserta didik menghadirkan suatu pemikiran yang produktif. Keadaan ini menjadi tantangan bagi guru yang melaksanakan pembelajaran. Hal ini mengingat mewujudkan berpikir produktif tidak tepas kekuatan daya nalar dan pengalaman yang dimiliki seorang guru. Kemampuan dalam berpikir produktif tentu akan mendorong kualitas pembelajaran (Lince, 2016). Guru sangat ditutut untuk meningkatkan profesionalitas dan kompetensi berpikir secara kreatif sehingga melahirkan ide-ide produktif pada peserta didik. Melalui kreativitas guru, bisa membantu peserta didik secara kritis dan kreatif dalam berpikir hingga 75,6\%. Hal ini memberikan ruang kepada peserta didik untuk mendapatkan pemahaman yang baik dari aktivitas belajarnya (Plotnikova \& Strukov, 2019).

Sementara itu, dimensi penataan tugas merupakan bagian penting yang harus diperhatikan bagi seorang guru. Guru harus mengatur dan menata tugasnya dengan baik. Hal ini dilakukan untuk memudahkan guru dalam melaksanakan tugasnya. Melalui penataan tugas yang terstruktur dan sistematis akan memudahkan guru dalam bertindak. Penataan tugas ini sebagai langkah untuk meningkatkan efektifitas kerja sehingga tujuan dapat dengan mudah dicapai (Armiati, 2015). Sebaliknya, guru yang tidak menata tugas dapat mempersulit dalam penyelesaiannya. Burke (2011) menjelaskan bahwa sulit bagi guru dalam merancang dan mengimplementasikan kerjanya secara efektif. Keadaan ini dapat mengganggu kualitas dan produktifitas kerja seorang guru, terutama dalam hal pembelajaran. Sadar maupun tidak sadar, penataan tugas bagian manajemen kerja dapat memberikan dampak perubahan pada perilaku seorang guru (Graham, 2007). Tindakan yang tertata dalam belajar, baik terkait dengan tugas maupun tindakan instruksional mampu mendorong peserta didik mengerti dan mamahami pembelajaran yang dilaksanakan (Anderson \& Pešikan, 2016). Artinya, guru-guru yang sudah terbiasa dalam menata tugasnya, memberikan potensi yang baik dalam kegiatan belajar mengajar. 


\section{Korelasi Dimensi}

Pada data sebelumnya diketahui bahwa ada tiga butir pernyataan tidak valid sehingga berdampak pada interpretasi umum data korelasi penataan tugas. Data-data yang memiliki bintang dua pada angka tersebut menunjukkan kualitas korelasi (Zulhafizh, 2020; Haya, 2015) atau pada tingkat kepercayaan 0,99 \% (Ma, $\mathrm{Du}, \&$ Matusik, 2020). Data korelasi dimensi strategi berinovasi dapat diamati di tabel 2.

Tabel 2. Korelasi Product Moment

\begin{tabular}{|c|c|c|c|c|c|c|c|c|c|c|}
\hline Dimensi & SB & 1 & 2 & 3 & 4 & 5 & 6 & 7 & 8 & 9 \\
\hline Penguasaan informasi & $0,933^{* *}$ & 1 & & & & & & & & \\
\hline $\begin{array}{l}\text { Membangun } \\
\text { kepribadian }\end{array}$ & $0,902^{* *}$ & $0,830^{* *}$ & 1 & & & & & & & \\
\hline Berpikir produktif & $0,840^{* *}$ & $0,814^{* *}$ & $0,736^{* *}$ & 1 & & & & & & \\
\hline Manajerial tugas & $0,883^{* *}$ & $0,835^{* *}$ & $0,785^{* *}$ & $0,653^{* \star}$ & 1 & & & & & \\
\hline $\begin{array}{l}\text { Memberdayakan } \\
\text { teknologi }\end{array}$ & $0,842^{* *}$ & $0,780^{* *}$ & $0,741^{* *}$ & $0,738^{* \star}$ & $0,761^{* *}$ & 1 & & & & \\
\hline Realisasi kurikulum & $0,844^{* *}$ & $0,767^{\star *}$ & $0,776^{* *}$ & $0,658^{* *}$ & $0,747^{\star *}$ & $0,730^{* *}$ & 1 & & & \\
\hline $\begin{array}{l}\text { Pelaksanaan } \\
\text { pembelajaran }\end{array}$ & $0,927^{* *}$ & $0,851^{* *}$ & $0,816^{* *}$ & $0,703^{* \star}$ & $0,844^{* *}$ & $0,752^{* *}$ & $0,825^{* *}$ & 1 & & \\
\hline Rekayasa media & $0,467^{* *}$ & $0,352^{* *}$ & $0,298^{* *}$ & $0,501^{* *}$ & $0,261^{* *}$ & $0,381^{* *}$ & $0,205^{*}$ & $0,287^{* *}$ & 1 & \\
\hline Penataan tugas & 0,055 & $-0,059$ & $-0,051$ & $-0,026$ & $-0,080$ & $-0,116$ & $-0,119$ & $-0,092$ & $0,304^{* *}$ & 1 \\
\hline
\end{tabular}

ND: SB (Strategi Berinovasi), ** (bermakna berkorelasi dengan sign. 0,05 )

Pada tabel 2 ini memperlihatkan bahwa dimensi penataan tugas pada analisis data respon guru sekolah menengah terkait dengan tindakan berinovasi tidak begitu relevan dengan dimensi lainnya. Dimensi yang tidak relevan dengan dimensi lainnya menunjukkan bahwa penataan tugas di sekolah tempat para guru bertugas bukan hal yang urgen untuk menjamin mutu pendidikan dan pembelajaran. Kegiatan penataan tugas bagian dari kegiatan manajemen dan secara analisis berkorelasi dengan dimensi lain dalam mencermati inovasi para guru. Chu et al (2011) menjelaskan bahwa kemampuan manajerial seorang guru sangat membantu dalam menjalankan tugasnya, bahkan dengan kemampuan yang ada dapat meningkatkan kinerja dan mutu pembelajaran bersama peserta didik. Lim, et al (2003) menegaskan bahwa pembelajaran akan kondusif jika dilaksanakan proses manajemen dengan efektif dan terpelihara. Ditambah jika para guru memiliki pengetahuan dan pemahaman yang baik terhadap materi dan informasi, daya nalar, penggunaan dan rekayasa teknologi tertata baik.

\section{Anova Satu Arah}

Sebagai analisis lanjutan dilakukan tindakan Anova satu arah untuk menentukan perbedaan masing-masing dimensi terhadap varian antar kelompok maupun dalam kelompok. Terdapat perbedaan yang signifikan untuk dimensi penguasaan informasi $\left(F_{h} 29,059>F_{t} 1,530=0,000<0,05\right)$, membangun kepribadian $\left(F_{h}\right.$ $\left.23,005>F_{t} 1,530=0,000<0,05\right)$, berpikir produktif $\left(F_{h} 7,495>F_{t} 1,530=0,000<0,05\right)$, manajerial tugas $\left(F_{h} 13,730>F_{t} 1,530=0,000<0,05\right)$, memberdayakan teknologi $\left(F_{h} 9,756>F_{t} \quad 1,530=0,000<0,05\right)$, realisasi kurikulum $\left(\mathrm{F}_{\mathrm{h}} 8,368>\mathrm{F}_{\mathrm{t}} 1,530=0,000<0,05\right)$, pelaksanaan pembelajaran $\left(\mathrm{F}_{\mathrm{h}} 20,884>\mathrm{F}_{\mathrm{t}} 1,530=\right.$ $0,000<0,05)$, dan rekayasa media $\left(F_{h} 2,947>F_{t} 1,530=0,000<0,05\right)$. Namun untuk penataan tugas tidak menunjukkan perbedaan yang signifikan untuk mengetahui strategi berinovasi guru sekolah menengah Indonesia, yaitu nilai $\mathrm{F}_{\mathrm{h}} 1,302<\mathrm{F}_{\mathrm{t}} 1,530=0,170>0,05$, data ditunjukkan pada tabel 3 .

Pada tabel 3 ini memberikan penguatan bahwa dimensi penguasaan informasi, membangun kepribadian, berpikir produktif, manajerial tugas, memberdayakan teknologi, realisasi kurikulum, pelaksanaan pembelajaran, dan rekayasa media tidak sama antar dimensi dan dapat menjadi dasar pengamatan terhadap strategi berinovasi oleh guru Sekolah Menengah Atas Kota Pekanbaru. Lain halnya pada dimensi penataan tugas, tidak dapat dijadikan sebagai dasar untuk mengamati strategi berinovasi para guru. Maka, perioritas pengamatan dapat dilihat selain aspek dimensi penataan tugas hal ini mengingat penataan tugas sudah bagian dari manajerial. Nakpodia (2010) menyatakan bahwa manajerial yang dilakukan seseorang guru sebagai langkah untuk mencapai yang diinginkan. 
Tabel 3. Skor Anova Dua Arah Strategi Berinovasi

\begin{tabular}{|c|c|c|c|c|c|c|c|}
\hline Dimensi & Sumber Varian & $\begin{array}{l}\text { Jumlah } \\
\text { Kuadrat }\end{array}$ & $\mathbf{d f}$ & $\begin{array}{c}\text { Rata-rata } \\
\text { Kuadrat }\end{array}$ & $\mathbf{F}_{\mathrm{h}}$ & $F_{t}$ & Sig. \\
\hline \multirow[t]{3}{*}{ Penguasaan informasi } & Antar kelompok & 694,732 & 37 & 18,777 & \multirow{3}{*}{29,059} & \multirow{3}{*}{1,530} & \multirow{3}{*}{0,000} \\
\hline & Dalam kelompok & 45,231 & 70 & 0,646 & & & \\
\hline & Total & 739,963 & 107 & & & & \\
\hline \multirow{3}{*}{$\begin{array}{l}\text { Membangun } \\
\text { kepribadian }\end{array}$} & Antar kelompok & 693,899 & 37 & 18,754 & \multirow{3}{*}{23,005} & \multirow{3}{*}{1,530} & \multirow{3}{*}{0,000} \\
\hline & Dalam kelompok & 57,064 & 70 & 0,815 & & & \\
\hline & Total & 750,963 & 107 & & & & \\
\hline \multirow[t]{3}{*}{ Berpikir produktif } & Antar kelompok & 188,519 & 37 & 5,095 & \multirow{3}{*}{7,495} & \multirow{3}{*}{1,530} & \multirow{3}{*}{0,000} \\
\hline & Dalam kelompok & 47,583 & 70 & 0,680 & & & \\
\hline & Total & 236,102 & 107 & & & & \\
\hline \multirow[t]{3}{*}{ Manajerial tugas } & Antar kelompok & 337,717 & 37 & 9,127 & \multirow{3}{*}{13,730} & \multirow{3}{*}{1,530} & \multirow{3}{*}{0,000} \\
\hline & Dalam kelompok & 46,533 & 70 & 0,665 & & & \\
\hline & Total & 384.250 & 107 & & & & \\
\hline \multirow{3}{*}{$\begin{array}{l}\text { Memberdayakan } \\
\text { teknologi }\end{array}$} & Antar kelompok & 123,838 & 37 & 3,347 & \multirow{3}{*}{9,756} & \multirow{3}{*}{1,530} & \multirow{3}{*}{0,000} \\
\hline & Dalam kelompok & 24,014 & 70 & 0,343 & & & \\
\hline & Total & 147,852 & 107 & & & & \\
\hline \multirow[t]{3}{*}{ Realisasi kurikulum } & Antar kelompok & 190,185 & 37 & 5,140 & \multirow{3}{*}{8,368} & \multirow{3}{*}{1,530} & \multirow{3}{*}{0,000} \\
\hline & Dalam kelompok & 43,000 & 70 & 0,614 & & & \\
\hline & Total & 233,185 & 107 & & & & \\
\hline \multirow{3}{*}{$\begin{array}{l}\text { Pelaksanaan } \\
\text { pembelajaran }\end{array}$} & Antar kelompok & 1529,444 & 37 & 41,336 & \multirow{3}{*}{20,884} & \multirow{3}{*}{1,530} & \multirow{3}{*}{0,000} \\
\hline & Dalam kelompok & 138,556 & 70 & 1,979 & & & \\
\hline & Total & 1668,000 & 107 & & & & \\
\hline \multirow[t]{3}{*}{ Rekayasa media } & Antar kelompok & 135,052 & 37 & 3,650 & \multirow{3}{*}{2,947} & \multirow{3}{*}{1,530} & \\
\hline & Dalam kelompok & 86,689 & 70 & 1,238 & & & 0,000 \\
\hline & Total & 221,741 & 107 & & & & \\
\hline Penataan tugas & Antar kelompok & 100,244 & 37 & 2,709 & & & \\
\hline & Dalam kelompok & 145,608 & 70 & 2,080 & 1,302 & 1,530 & 0,170 \\
\hline & Total & 245,852 & 107 & & & & \\
\hline
\end{tabular}

\section{Koefisiensi Determinan (R)}

Data-data yang tidak signifikan melalui analisis Anova satu arah secara jelas tidak memberikan sumbangan yang berarti. Sumbangan yang diberikan sangat kecil atau rendah dalam hal strategi berinovasi para guru sekolah menengah. Pada tabel 8 memperlihatkan perbandingan antar masing-masing dimensi.

Jika dilihat secara persatuan dimensi terhadap strategi berinovasi, maka penguasaan informasi bisa memberikan pengaruh sebesar 0,866 pada prediktor 0,865 ; membangun kepribadian bisa memberikan pengaruh sebesar 0,829 pada prediktor 0,827 ; berpikir produktif bisa memberikan pengaruh sebesar 0,712 pada prediktor 0,709; manajerial tugas bisa memberikan pengaruh sebesar 0,845 pada prediktor 0,843 ; memberdayakan teknologi bisa memberikan pengaruh sebesar 0,728 pada prediktor 0,726 ; realisasi kurikulum bisa memberikan pengaruh sebesar 0,727 pada prediktor 0,724 ; pelaksanaan pembelajaran bisa memberikan pengaruh sebesar 0,867 pada prediktor 0,866 ; rekayasa media bisa memberikan pengaruh sebesar 0,411 pada prediktor 0,406; dan penataan tugas bisa memberikan pengaruh sebesar 0,084 pada prediktor 0,075 . Pada penataan tugas lebih rendah dibandingkan dengan dimensi lain. Hal ini menguatkan bahwa data tersebut tidak memberikan peran yang signifikan (seperti pada tabel 2 dan 3). 
Tabe1 4. Nilai Koefisiensi Determinan terhadap Strategi Berinovasi

\begin{tabular}{lcc}
\hline \multicolumn{1}{c}{ Dimensi } & R Kuadrat & Prediktor R Kuadrat \\
\hline Penguasaan informasi & 0,866 & 0,865 \\
Membangun kepribadian & 0,829 & 0,827 \\
Berpikir produktif & 0,712 & 0,709 \\
Manajerial tugas & 0,845 & 0,843 \\
Memberdayakan teknologi & 0,728 & 0,726 \\
Realisasi kurikulum & 0,727 & 0,724 \\
Pelaksanaan pembelajaran & 0,867 & 0,866 \\
Rekayasa media & 0,411 & 0,406 \\
Penataan tugas & 0,084 & 0,075 \\
\hline
\end{tabular}

\section{Strategi Berinovasi}

Strategi berinovasi sebagai sebuah upaya dalam menghadirkan hal-hal yang lebih maju dan lebih baik. Sebelum melakukan tindakan yang bersifat inovatif, guru perlu memikirkan hal-hal yang dapat mengantarkan ke arah yang inovatif. Hasil studi memperlihatkan terdapat sembilan strategi guru agar dapat mengantarkan mereka untuk berinovasi di sekolah menengah: penguasaan informasi, membangun kepribadian, berpikir produktif, manajerial tugas, memberdayakan teknologi, realisasi kurikulum, pelaksanaan pembelajaran, rekayasa media, dan penataan tugas (Toropova et al, 2021; Mykhailyshyn et al, 2018; Lawrence \& Tar, 2018; Suriansyah, 2015; Rubie-Davies et al, 2015). Dari sembilan strategi tersebut terdapat satu dimensi, yaitu penataan tugas tidak signifikan. Namun demikian, penataan tugas tetap memberikan sumbangan terhadap langkah guru untuk melahirkan inovasi di Sekolah Menengah Atas.

Pada analisis instrumen menunjukkan para guru di Sekolah Menengah Atas di Kota Pekanbaru berupaya menguasai informasi untuk mereka berkompeten dalam menyajikan materi atau mentransfer informasi. Cara yang ditempuh yaitu memahami materi yang akan diajarkan ke peserta didik, membaca berbagai sumber baik cetak maupun online, mencari sumber-sumber terkini, mengikuti diklat/workshop/seminar, bahkan yang tidak kalah pentingnya adalah mereka mengikuti dan membuat karya ilmiah seperti PTK. Cata ini menjadi penguat agar para guru memiliki pengetahuan dan informasi yang dapat membantu peserta didik dalam belajar. Secara keseluruan, upaya yang ditempun para guru berkategori tinggi. Dari semua aktivitas yang dilakukan guru, membuat karya ilmiah masih tergolong rendah. Hal ini mengingat, tidak semua guru terampil dalam menulis. Shaughnessy (2012) untuk bisa menulis, para guru harus memiliki banyak wawasan atau menguasai berbagai informasi. Ültay dan Usta (2016) memberikan kesimpulan bahwa aktifitas menulis guru masih belum memadai, khususnya menurut Mudavanhu (2017) dalam hal publikasi.

Para guru juga membangun kepribadian yang baik berguna dalam bersikap dan berkomunikasi. Cara yang mereka lakukan adalah berupaya tetap ramah dalam dengan semua lingkungan sekolah, penuh tanggung jawab, berkomunikasi dengan baik, disiplin dalam menjalankan tugas, dan berusaha memberi contoh yang baik. Cara ini secara kompetensi kepribadian, memang sesuatu yang harus dilakukan bagi seorang guru. Para guru menyadari bahwa ia digugu dan ditiru oleh lingkungannya. Komarudin (2020) dalam penelitiannya bahwa kepribadian guru yang memiliki kepribadian yang baik dapat memberikan dampak pada lingkungan sekitarnya, khusus pada peserta didik dalam aktifitas pembelajaran. Nahampun (2017) kepribadian guru yang mantab dan stabil membawa rasa empati terhadap kondisi sekitarnya, baik peserta didik maupun teman sejawat. Kepribadian yang disiplin dan penuh tanggung jawab serta bisa memberikan contoh dapat menjadi titik tumpu dan penyeimbang (Safitri \& Refinaldi, 2020) dalam satuan pendidikan/sekolah.

Sebagai seorang guru, mereka dituntut berpikir secara produktif. Berpikir produktif dapat dimaknai mengembangkan ide-ide yang membangun. Aktivitas ini dapat dihadirkan dalam pembelajaran melalui bertanya-jawab dengan peserta didik atau menciptakan sistem pembelajaran berbasis masalah (Saputra, 2019). Hal ini sejalan dengan yang dilakukan para guru di Sekolah Menengah Atas di Kota Pekanbaru yaitu menyampaikan informasi untuk bisa mendapatkan timbal balik terhadap informasi tersebut, mengembangkan ide melalui berbagai keterampilan secara langsung, dan berupaya memberi tugas yang dapat membangun sikap kritis pada peserta didik. Coe et al (2014) guru-guru yang mengembangkan idenya secara produktif menjadi kunci keberhasilan dalam pembelajaran. Selain itu, dalam aktifitas berpikir seorang guru dalam melaksanakan pembelajaran tidak lepas pula dengan manajerialnya dalam menjalankan tugas. Para guru juga memikirkan upaya mengelola kelas dengan baik dan penuh disiplin agar segala kegiatan yang 
dilakukan selama aktivitas pembelajaran dapat tercapai dengan baik. Kemampuan manajerial seorang guru dalam pembelajaran dapat meningkatkan kinerjanya (Chu et al, 2011).

Di era saat ini, selain kemampuan manajerial dalam pembelajaran, guru juga juga tidak bisa lepas dari tuntutan pemanfaatan teknologi sebagai penguatan profesionalisme guru. Memberdayakan teknologi turut membantu guru dalam melaksanakan pembelajaran (Mustafa et al, 2019). Adanya teknologi memberikan ruang kepada guru untuk berkreasi dan berinovasi. Hampir guru yang profesional dan inovatif memberdayakan teknologi. Pemberdayaan teknologi diyakini dapat meningkatkan kualitas, memudahkan, dan mengefisiensi pembelajaran (Darnawati et al, 2019; Albirini, 2006). Upaya yang dilakukan para guru adalah membuat media sebagai fasilitas pembelajaran, melihat kebutuhan dan perkembangan teknologi, memanfaatkan komputer/labtor beserta sofware. Terkait dengan sofware ini, sangat beragam yang dimiliki guru, ada quipper school, gafe, edmodo, pawtoon, dan canva. Fasilitas yang mereka miliki sesuai dengan kebutuhan dan juga didorong masa masa pelatihan. Para guru bisa melakukan rekayasa media setelah memiliki fasilitas. Hasil suveinya mengungkapkan pemanfaatan teknologi membuat guru menjadi produktif (Means, 2010). Kotrlik dan Redmann (2009) mengungkapkan bahwa 99\% guru menggunakan teknologi inovatif ini di satuan pendidikan - tempat mereka bertugas.

Semua fasilitas yang dimiliki guru dapat menjadi media yang menunjang kegiatan pembelajaran. Hal yang harus disadari adalah kegagalan menggunakan media justru dapat mengakibatkan tujuan pembelajaran tidak dicapai dengan baik. Guru harus mengerti dan paham kegunaan setiap media yang digunakan dalam kegiatan pembelajaran. Ia harus mampu memilih dengan tepat agar penggunaan media atau fasilitas tersebut benar-benar dapat membantunya dalam pelaksanaan pembelajaran (Okongo et al, 2015). Cara yang ditempuh guru Sekolah Menengah Atas yaitu memanfaatkan fasilitas pembelajaran yang ada, menggunakan media sesuai tuntutan materi, membuat slide pembelajaran, menyusun LKS, membuat bahan ajar, memanfaatkan e-learning. Media yang dipilih dan digunakan serta direkayasa guru sebagai perantara untuk pembelajaran (Ediyani, 2020). Alfiyah et al (2016) menegaskan kemampuan guru dalam memanfaatkan media pembelajaran tidak sama. Setiap guru memiliki kemampuan berbeda-beda. Ramdhani dan Muhammadiyah (2015) guru harus memahami kriteria dan peranan masing-masing media akan digunakan seperti kesesuaian dengan tujuan belajar, metode yang digunakan, keadaan peserta didik, ketersediaan, dan efisiensi.

Guna menunjang realisasi strategi inovatif yang dilakukan guru Sekolah Menengah Atas adalah memahami tuntutan kurikulum. Prinsip yang dilakukan para guru adalah konsen menjalankan tuntutan kurikulum, menyiapkan perangkat sesuai dengan perkembangan, menyesuaikan materi dengan kondisi lingkungan, bahkan mereka juga memiliah konten yang sesuai dengan tuntutan lapangan dalam pengertian disesuaikan keadaan lokal dan peserta didik. Öztürk (2011) guru memiliki otonomi dalam mendesain pembelajarannya yang berlandaskan kurikulum. Pada poin ini tidak bisa dilepaskan sebagai usaha guru menyiapkan karir peserta didik di masa mendatang. Peran guru sangat diharapkan dalam setiap pelaksanaan kurikulum. Kesuksesan kurikulum pendidikan yang telah direncanakan ini tidak lepas dari sumbangsih dan peran aktif, kreatif, dan inovatif dari seorang guru. Yildirim (2003) berpandangna tidak semua yang direncanakan di kurikulum dapat berjalan dengan baik. Kurikulum yang berlaku secara nasional dapat membuat guru kesulitan menjalankannya karena tidak sesuai dengan kondisi realistis lapangan, bahkan tidak sesuai pula dengan latar belakang, kebutuhan, dan minat peserta didik. Kreativitas guru menjadi penentu untuk menyesaikan persoalan-persoalan yang diharapkan dalam kurikulum.

Realisasi kurikulum melekat pada pelaksanaan pembelajaran. Para guru mengambil inisiasi terkait dengan pelaksanaan pembelajaran yaitu: memikirkan karakter apa yang diberikan ke peserta didik, lalu memberikan motivasi-perhatian, memilih dan mendesain metode atau model pembelajaran yang sesuai dengan kebutuhan, membuat tahapan pembelajaran yang berbasis penyelesaian masalah, memberikan stimulus yang bervariasi sehingga pembelajaran tidak menoton. Seluruh aktivitas dilakukan para guru. Pada kontek ini, baik guru laki-laki atau perempuan maupun yang berstatus PNS atau non PNS memiliki ruang dan kesempatan yang sama dalam mendesai pembelajaran. Persoalan gender dan jenjang tidak membatasi untuk bisa berinovasi dalam pembelajaran (Kalpazidou Schmidt \& Cacace, 2019) maka berbagai berubahan dapat muncul dan berkembang untuk kemajuan sekolah, baik terkait pendidikan dan pengajaran.

Catatan penting dari aktivitas yang dilakukan adalah motivasi yang kuat dari guru untuk mencapai yang diinginkan (Kurniawan et al, 2019; Mustafa et al, 2018) dalam mewujudkan strategi tersebut. Semua dimensi kembali pada semua guru. Melalui analisis koefisensi determinan masing-masing dimensi mampu memberikan peran tersendiri bagi guru yang ingin berinovasi: penguasaan informasi bisa mencapai $86,6 \%$, membangun kepribadian $82,9 \%$, berpikir produktif bisa mencapai $71,2 \%$, manajerial tugas bisa mencapai $84,5 \%$, memberdayakan teknologi bisa mencapai $72,8 \%$, realisasi kurikulum bisa mencapai $72,7 \%$, pelaksanaan pembelajaran bisa mencapai $86,7 \%$, rekayasa media bisa mencapai $41,1 \%$, dan penataan tugas 
bisa mencapai 8,4\%. Para guru berkonsentasi pada penguasaan informasi, membangun kepribadian, manajerial tugas, dan pelaksanaan pembejaran. Porsi sumbangan ini lebih besar dibandingkan dimensi lain.

Peran dimensi tersebut bisa mencapai koefisiensi determinan seperti disampaikan sebelumnya apabila berada dalam kondisi yang stabil. Artinya, strategi ini sangat tepat pada guru sekolah menengah. Semua guru memiliki harapan yang sama agar bisa memberikan inovasi terbaik untuk peserta didiknya, rata-rata pada standar 4,722 dengan kategori sangat tinggi. Guru yang menerapkan pembelajaran kreatif menuntut adanya inovasi, seperti merancang rencana pembelajaran, menguraikan materi, mengevaluasi, dan menilai hasil belajar(Setianingrum \& Guntur, 2020); Daly et al, 2019; Tsai et al, 2018). Maka dapat dipastikan bawah tindakan-tindakan atau segala persiapan dan usaha kreatif merupakan suatu keharusan. Keadaan ini mampu mendorong guru dari keluar dari keterpurukan di sekolah (Waruwu et al, 2020).

Inovasi lahir dari segala proses yang diperlukan dan teratur, tidak spontan. Stukalenko et al (2016) inovasi yang akan dihadirkan di sekolah tidak bersifat spontan, tetapi lebih bersifat sadar dan diatur. Find1koğlu \& İlhan (2016) inovasi mendorong untuk melangkah lebih jauh ke depan. Kegiatan yang berinovatif tidak bersifat konstan, tetapi dimanis sehingga dilakukan usaha-usaha kreatif pula (Mustafa et al, 2021) yang dapat membangun sistem yang lebih baik dan efektif. Bahwa berinovasi sebagai langkah membuat perubahan_ke arah yang lebih baik_di masa depan (Liu, 2020; Massu et al, 2018). Pernyaaan tersebut secara eksplesit maupun implisit menekankan bahwa inovasi di sekolah sangat perlu dilakukan untuk meningkatkan kemajuan dan mutu pendidikan.

\section{Simpulan}

Berdasarkan hasil penelitian bahwa seorang guru harus berusaha membuat inovasi dengan berbagai strategi untuk membawa kemajuan yang lebih baik terhadap aktivitas di sekolah. Majunya sekolah tentu akan berdampak pada kemajuan dunia pendidikan. Ada hubungan yang signifikan penguasaan informasi, membangun kepribadian, berpikir produktif, manajerial tugas, memberdayakan teknologi, realisasi kurikulum, pelaksanaan pembelajaran, dan rekayasa media terhadap motivasi dan kreativitas guru dan memberikan dampak pada lingkungan sekolah. Masing-masing signifikansinya tidak melebih dari 0,000 atau tidak lebih besar dari $\mathrm{F}$ hitung. Sementara itu, dimensi penataan tugas tidak signifikan untuk mengungkapkan strategi berinovasi guru Sekolah Menengah Atas di Kota Pekanbaru, dimana tingkat signifikansinya melebih 0,000, yaitu 0,170 . Secara keseluruh melalui pendekatan rata-rata atau mean upaya guru dalam menerapkan semua dimensi berkategori tinggi yaitu 4,722 pada SD 0,302. Dimensi-dimensi ini sangat baik dikembangkan dan dijadikan indikator para guru yang berupaya untuk berinovasi di lingkungan Sekolah Menengah Atas di Kota Pekanbaru. Dimensi ini dapat memberikan manfaat bagi guru dalam peningkatan kualitas dan mutu pendidikan dan pembelajaran. Selain itu, guru-guru yang menjalankan dimensi tersebut dalam keseharian pembelajaran dapat meningkatkan profesionalitasnya.

\section{Referensi}

Albirini, A. (2006). Teachers' Attitudes Toward Information and Communication Technologies: The Case of Syrian EFL Teachers. Computers \& Education, 47(4), 373-398.

Alfiyah, H. Y., Fauziyah, A. N., \& Masfufah. (2016). Pengembangan Kapasitas Guru melalui Pengembangan Media Pembelajaran Interaktif Berbasis Teknologi Informasi di Minu Waru Sidoarjo. Jurnal Pendidikan Agama Islam, 4(1), 158-178.

Al-Imarah, A. A., \& Shields, R. (2019). MOOCs, Disruptive Innovation and the Future of Higher Education: A Conceptual Analysis. Innovations in Education and Teaching International, 56(3), 258-269.

Anderson, L. W., \& Pešikan, A. (2016). Task, Teaching and Learning: Improving the Quality of Education for Economically Disadvantaged Students. France: International Academyof Education, Unesco, \& International Bureau Of Education.

Armiati. (2015). Meningkatkan Efektivitas Kerja Pegawai melalui Penataan Layout Kantor. Prosiding Seminar Nasional Ekonomi Manajemen dan Akuntansi (SNEMA) Fakultas Ekonomi Universitas Negeri Padang, Padang, Indonesia, 334-343.

Astrawan, I. K. V., Martha, I. N., \& Artika, I. W. (2019). Application of Saintific-Innovative Learning Models in Indonesian Teachers. Jurnal Penelitian dan Pengembangan Sains dan Humaniora, 3(1), 51-60.

Bahri, A., Idris, I. S., Muis, H., Arifuddin, M., \& Fikri, M. (2021). Blended Learning Integrated with Innovative Learning Strategy to Improve Self-Regulated Learning. International Journal of Instruction, 14(1), 779-794. 
Bowden, J., Davey Smith, G., \& Burgess, S. (2015). Mendelian Randomization with Invalid Instruments: Effect Estimation and Bias Detection Through Egger Regression. International Journal of Epidemiology, 44(2), 512-525.

Burke, A. (2011). Group Work: How to use Groups Effectively. The Journal of Effective Teaching, 11(2), 87-95.

Castleberry, A., Ward, W., \& Stein, S. (2019). Lifelong Learning Inspires the Creative Art of Academic Writing. Currents in Pharmacy Teaching and Learning, 11(8), 757-759.

Chu, K.W., Wang, M., \& Yuen, A. H. K. (2011). Implementing Knowledge Management in School Environment: Teachers' Perception. Knowledge Management \& E-Learning: An International Journal, 3(2), 139-152.

Daly, S. R., Mosyjowski, E. A., \& Seifert, C. M. (2019). Teaching Creative Process Across Disciplines. The Journal of Creative Behavior, 53(1), 5-17.

Darnawati, D., Jamiludin, J., Batia, L., Irawaty, I., \& Salim, S. (2019). Pemberdayaan Guru Melalui Pengembangan Multimedia Pembelajaran Interaktif Dengan Aplikasi Articulate Storyline. Amal Ilmiah: Jurnal Pengabdian Kepada Masyarakat, 1(1), 8-16.

De Smul, M., Heirweg, S., Van Keer, H., Devos, G., \& Vandevelde, S. (2018). How Competent do Teachers Feel Instructing Self-Regulated Learning Strategies? Development and Validation of the Teacher SelfEfficacy Scale to Implement Self-Regulated Learning. Teaching and Teacher Education, 71, 214-225.

Ediyani, M., Hayati, U., Salwa, S., Samsul, S., Nursiah, N., \& Fauzi, M. B. (2020). Study on Development of Learning Media. Budapest International Research and Critics Institute-Journal (BIRCI-Journal), 3(2), 13361342 .

Ekayanti, N. W., Arjaya, I. B. A., \& Anggraini, N. K. (2020). Photomapping: Mengasah Kreativitas Siswa dengan Photografi. Indonesian Journal of Educational Science (IJES), 2(2), 72-80.

Ernawati, I. (2017). Uji Kelayakan Media Pembelajaran Interaktif pada Mata Pelajaran Administrasi Server. Elinvo (Electronics, Informatics, and Vocational Education), 2(2), 204-210.

Fadli, R. I., Nugraha, A. S., Raharjo, R. P., \& Sulton, A. (2020). Model Pembelajaran Inovatif Guru SMA Abdul Hadi dengan Strategi Literasi. ABIDUMASY Jurnal Pengabdian kepada Masyarakat, 1(1), 1-12.

Findikoğlu, F. \& İlhan, D. (2016). Realization of A Desired Future: Innovation in Education. Universal Journal of Educational Research, 4(11), 2574-2580.

Firmadani, F. (2020). Media Pembelajaran Berbasis Teknologi sebagai Inovasi Pembelajaran Era Revolusi Industri 4.0. KoPeN: Konferensi Pendidikan Nasional, 2(1), 93-97.

Graham, P. (2007). Improving Teacher Effectiveness Through Structured Collaboration: A Case Study of a Professional Learning Community. Research in Middle Level Education-Online (RMLEOnline), 31(1), 1-17.

Güçlü Yilmaz, F. (2021). Innovative Practices in Turkish Education System According to Teacher Perceptions. Anatolian Journal of Education, 6(1), 175-190.

Hamza, M. K., \& Griffith, K. G. (2006). Fostering Problem-Solving \& Creative Thinking in the Classroom: Cultivating A Creative Mind. In National Forum of Applied Educational Research Journal-Electronic, 9(3), 132.

Hapsari, I. I., \& Fatimah, M. (2021). Inovasi Pembelajaran sebagai Strategi Peningkatan Kualitas Guru di SDN 2 Setu Kulon. Prosiding dan Web Seminar (Webinar) Cirebon, 28 Juni 2021, 187-194.

Hartini, S. (2016). Efektifitas Endorsment pada Media Sosial Instagram pada Produk Skin Care. Bina Insani ICT Journal, 3(1), 43-50.

Haya, P. A., Daems, O., Malzahn, N., Castellanos, J., \& Hoppe, H. U. (2015). Analysing Content and Patterns of Interaction for Improving the Learning Design of Networked Learning Environments. British Journal of Educational Technology, 46(2), 300-316.

Hornstra, L., van der Veen, I., Peetsma, T., \& Volman, M. (2015). Innovative Learning and Developments in Motivation and Achievement in Upper Primary School. Educational Psychology, 35(5), 598-633.

Jayalath, C., Wickramasinghe, U., Kottage, H., \& Somaratna, G. (2020). Factors Influencing Orderly Transition to Online Deliveries During COVID 19 Pandemic Impact. Asian Journal of Education and Social Studies, 10-24.

Kalpazidou Schmidt, E., \& Cacace, M. (2019). Setting up a Dynamic Framework to Activate Gender Equality Structural Transformation in Research Organizations. Science and Public Policy, 46(3), 321-338.

Kii, O. A., \& Dewa, E. (2020). Simulasi Phet sebagai Media Pembelajaran Berbasis Komputer pada Model Pembelajaran Team Games Tournament untuk Meningkatkan Aktivitas dan Hasil Belajar Fisika Mahasiswa. Jurnal Riset Teknologi dan Inovasi Pendidikan (JARTIKA), 3(2), 360-367.

Komarudin, E. (2020). Pengaruh Kompetensi Kepribadian dan Sosial Guru terhadap Motivasi Belajar Siswa SD Muhammadiyah Kadisoro II. G-Couns: Jurnal Bimbingan dan Konseling, 5(1), 9-14.

Koriaty, S., \& Agustani, M. D. (2017). Pengembangan Model Pembelajaran Game Edukasi untuk Meningkatkan Minat Siswa Kelas X TKJ SMK Negeri 7 Pontianak. Edukasi: Jurnal Pendidikan, 14(2), 277-288. 
Kotrlik, J.W., \& Redmann, D. H. (2009). Technology Adoption for Use in Instruction by Secondary Technology Education Teachers. Journal of Technology Education, 21(1), 44-59.

Kurniawan, D. A., Perdana, R., \& Nugroho, P. (2019). Supporting Technology 4.0: Ethoconstructivist Multimedia for Elementary Schools. International Journal of Online \& Biomedical Engineering, 15(14), 5466.

Lawrence, J. E., \& Tar, U. A. (2018). Factors that Influence Teachers' Adoption and Integration of ICT in Teaching/Learning Process. Educational Media International, 55(1), 79-105.

Lee, Y. J. (2008). A Study of the Influence of Instructional Innovation on Learning Satisfaction and Study Achievement. The Journal of Human Resource and Adult Learning, 4(2), 43-54.

Lince, R. (2016). Creative Thinking Ability to Increase Student Mathematical of Junior High School by Applying Models Numbered Heads Together. Journal of Education and Practice, 7(6), 206-212.

Liu, J., Zhao, X., \& Zhao, C. (2020). Stimulating and Educating Engineers to Innovate Through Individual Continuous Learning. Sustainability, 12(3), 843.

Lubis, K. M. (2011). Peningkatan Aktivitas Pembelajaran Hidrosfer dan Dampaknya Terhadap Kehidupan melalui Tindakan Guru Inovatif pada Kelas X di SMA Negeri 1 Semarang. Jurnal Geografi: Media Informasi Pengembangan dan Profesi Kegeografian, 8(1), 21-32.

Ma, P., Du, T., \& Matusik, W. (2020). Efficient Continuous Pareto Exploration in Multi-Task Learning. In International Conference on Machine Learning (pp. 6522-6531). PMLR.

Mashuri, S., Djidu, H., \& Ningrum, R. K. (2019). Problem-Based Learning dalam Pembelajaran Matematika: Upaya Guru untuk Meningkatkan Minat dan Prestasi Belajar Siswa. Pythagoras: Jurnal Pendidikan Matematika, 14(2), 112-125.

Massu, J., Caroff, X., Souciet, H., \& Lubart, T. I. (2018). Managers' Intention to Innovate in a Change Context: Examining the Role of Attitudes, Control and Support. Creativity Research Journal, 30(4), 329338.

Means, B. (2010). Technology and Education Change: Focus on Student Learning. Journal of Research on Technology in Education (JRTE), 42(3), 285-307.

Moore, M. L., Olsson, P., Nilsson, W., Rose, L., \& Westley, F. R. (2018). Navigating Emergence and System Reflexivity as Key Transformative Capacities. Ecology and Society, 23(2), 38.

Mudavanhu, Y. (2017). Quality of Literature Review and Discussion of Findings in Selected Papers on Integration of ICT in Teaching, Role of Mentors, and Teaching Science Through Science, Technology, Engineering, and Mathematics (STEM). Educational Research and Reviews, 12(4), 189-201.

Mustafa, M. N., Hermandra, \& Zulhafizh. (2019). Teachers' Strategies to Design Media to Implement Communicative Leaning in Public Schools. Journal of Educational Sciences, 3(1), 13-24.

Mustafa, M. N., Hermandra, Zulhafizh, \& Hermita, N. (2018). The Significance of Language Motivation Learning: Correlation Analysis. Advanced Science Letters, 24(11), 8380-8383.

Mustafa, M. N., Hermandra, Zulhafizh, \& Hidayat, R. (2021). Indonesian Secondary Teachers' Creative Teaching. Ilkogretim Online, 20(1), 1176-1184.

Mykhailyshyn, H., Kondur, O., \& Serman, L. (2018). Innovation of Education and Educational Innovations in Conditions of Modern Higher Education Institution. Journal of Vasyl Stefanyk Precarpathian National University, 5(1), 9-16.

Nahampun, D. (2017). Kompetensi Kepribadian Guru dalam Pelaksanaan Pembelajaran Anak Autis di SLB C Karya Bhakti Purworejo. Jurnal Widia Ortodidaktika, 6(5), 538-546.

Nakpodia, E. D. (2010). Teachers' Disciplinary Approaches to Students' Discipline Problems in Nigerian Secondary Schools . International NGO Journal, 56, 144-151.

Nicholls, A. (2018). Managing Educational Innovations. Autralia: Routledge.

Nurhadi, A. (2018). Manajemen Laboratorium dalam Upaya Meningkatkan Mutu Pembelajaran. Tarbawi: Jurnal Keilmuan Manajemen Pendidikan, 4(01), 1-12.

Okongo, R. B., Ngao, G., Rop, N. K., \& Wesonga, J. N. (2015). Effect of Availability of Teaching and Learning Resources on the Implementation of Inclusive Education in Pre-School Centers in Nyamira North Sub-County, Nyamira County, Kenya. Journal of Education and Practice, 6(35), 132-141.

Öztürk, I.H. 2011. Curriculum Reform and Teacher Autonomy in Turkey: The Case of the History Teaching. International Journal of Instruction, 4(2), 113-128.

Plotnikova, N. F., \& Strukov, E. N. (2019). Integration of Teamwork and Critical Thinking Skills in the Process of Teaching Students. Cypriot journal of educational sciences, 14(1), 1-10.

Prajana, A., \& Astuti, Y. (2020). Pemanfaatan Teknologi Informasi dan Komunikasi dalam Pembelajaran oleh Guru SMK di Banda Aceh dalam Upaya Implementasi Kurikulum 2013. JINOTEP (Jurnal Inovasi dan Teknologi Pembelajaran): Kajian dan Riset Dalam Teknologi Pembelajaran, 7(1), 33-41.

Pramayogi, I., \& Hartanto, W. (2019). Inovasi Pembelajaran Sejarah. SINDANG: Jurnal Pendidikan Sejarah dan Kajian Sejarah, 1(2), 17-22. 
Rahmati, N. H. (2020). Innovation in Education: Barriers and Facilitating Factors. European Journal of Education Studies, 6(10), 56.

Ramdhani, M.A., \& Muhamadiyah, H. (2016). The Criteria of Learning Media Selection for Character Education in Higher Education. Proceeding International Conference of Islamic Education: Reforms, Prospects and Challenges Faculty of Tarbiyah and Teaching Training, Maulana Malik Ibrahim State Islamic University, Malang, 2-3 December, 174-182.

Ramsey, P. L., \& Khan, S. (2021). Dilemmas, Emotion and Innovation in Tertiary Education. Innovations in Education and Teaching International, 58(3), 250-260.

Revathi, G., Elavarasi, S., \& Saravanan, K. (2019). Innovative Methods of Teaching and Learning for Education. Journal of Emerging Technologies and Innovative Research (JETIR), 6(5), 159-163.

Rochman, B., Indahwati, N., \& Priambodo, A. (2020). Identifikasi Keterlaksanaan Pembelajaran PJOK Tingkat SMP di Masa Pandemi Covid 19 se-Kabupaten Sidoarjo. Jurnal Ilmiah Mandala Education, 6(1), 256-165.

Rubie-Davies, C. M., Peterson, E. R., Sibley, C. G., \& Rosenthal, R. (2015). A Teacher Expectation Intervention: Modelling the Practices of high Expectation Teachers. Contemporary Educational Psychology, 40, 72-85.

Safitri, A., \& Refinaldi, R. (2020). Urgensi Kompetensi Kepribadian Guru dalam Pembelajaran Sejarah. Tarikhuna: Journal of History and History Education, 2(2), 77-84.

Saputra, M. D., Joyoatmojo, S., Wardani, D. K., \& Sangka, K. B. (2019). Developing Critical-Thinking Skills Through the Collaboration of Jigsaw Model with Problem-Based Learning Model. International Journal of Instruction, 12(1), 1077-1094.

Setianingrum, R., \& Guntur, G. (2020). Evaluation of Civil Servant Teacher's Restructuring and Equalizing Policy at Vocational High School. Jurnal Penelitian dan Evaluasi Pendidikan, 24(1), 1-14.

Setiawan, A. R. (2020). Peningkatan Literasi Saintifik melalui Pembelajaran Biologi Menggunakan Pendekatan Saintifik. Journal of Biology Education, 2(1), 1-13.

Shalikhah, N. D. (2017). Media Pembelajaran Interaktif Lectora Inspire sebagai Inovasi Pembelajaran. Warta LPM, 20(1), 9-16.

Shardell, M., \& Ferrucci, L. (2016). Instrumental Variable Analysis of Multiplicative Models with Potentially Invalid Instruments. Statistics in Medicine, 35(29), 5430-5447.

Shaughnessy, A. F., Gupta, P. S., Erlich, D. R., \& Slawson, D. C. (2012). Ability of An Information Mastery Curriculum to Improve Residents' Skills and Attitudes. Family Medicine, 44(4), 259-264.

Sithole, A., Kibirige, J., Mupinga, D. M., \& Chiyaka, E. T. (2016). Applying Alternative Teaching Methods to Impart a Rounded, Liberal Arts and Sciences (LAS) Education: Students' Reflections on the Role of Magazines as Instructional Tools. Journal of Education and Practice, 7(33), 176-182.

Stukalenko, N.M. 2016. Studying Innovation Technologies in Modern Education. International Journal of Environmental \& Science Education, 11(15), 7297-7308.

Suriansyah, A. (2015). Strategi Kepemimpinan Kepala Sekolah, Guru, Orang Tua, dan Masyarakat dalam Membentuk Karakter Siswa. Jurnal Cakrawala Pendidikan, 34(2), 234-247.

Suryaman, M., Cahyono, Y., Muliansyah, D., Bustani, O., Suryani, P., Fahlevi, M., \& Munthe, A. P. (2020). Covid-19 Pandemic and Home Online Learning System: Does it Affect the Quality of Pharmacy School Learning. Systematic Reviews in Pharmacy, 11(8), 524-530.

Susilo, A. A., \& Sofiarini, A. (2020). Peran Guru Sejarah dalam Pemanfaatan Inovasi Media Pembelajaran. Jurnal Komunikasi Pendidikan, 4(2), 79-93.

Swanson, S. A. (2019). A Practical Guide to Selection Bias in Instrumental Variable Analyses. Epidemiology, 30(3), 345-349.

Toropova, A., Myrberg, E., \& Johansson, S. (2021). Teacher Job Satisfaction: the Importance of School Working Conditions and Teacher Characteristics. Educational Review, 73(1), 71-97.

Tsai, C. Y., Chang, Y. H., \& Lo, C. L. (2018). Learning Under Time Pressure: Learners Who Think Positively Achieve Superior Learning Outcomes from Creative Teaching Methods using Picture Books. Thinking Skills and Creativity, 27, 55-63.

Ültay, N., \& Usta, N. D. (2016). Investigating Prospective Teachers` Ability to Write Context-Based Problems. Journal of Theory and Practice in Education, 12(2), 447-463.

Ulumudin, I., \& Fujianita, S. (2019). The Implementation of Attitude Assessment in Curriculum 2013 at Elementary Schools. Jurnal Penelitian dan Evaluasi Pendidikan, 23(1), 46-56.

Ünal, M. (2017). Preferences of Teaching Methods and Techniques in Mathematics with Reasons. Universal Journal of Educational Research, 5(2), 194-202.

van der Rijst, R., Baggen, Y., \& Sjoer, E. (2019). University Teachers' Learning Paths During Technological Innovation in Education. International Journal for Academic Development, 24(1), 7-20. 
Wang, X., Jiang, Y., Zhang, N. R., \& Small, D. S. (2018). Sensitivity Analysis and Power for Instrumental Variable Studies. Biometrics, 74(4), 1150-1160.

Warnock, J. N., \& Mohammadi-Aragh, M. J. (2016). Case Study: Use of Problem-Based Learning to Develop Students' Technical and Professional Skills. European Journal of Engineering Education, 41(2), 142-153.

Waruwu, H., Asbari, M., Purwanto, A., Nugroho, Y. A., Fikri, M. A. A., Fauji, A., .. \& Dewi, W. R. (2020). The Role of Transformational Leadership, Organizational Learning, and Structure on Innovation Capacity: Evidence from Indonesia Private Schools. EduPsyCouns: Journal of Education, Psychology and Counseling, 2(1), 378-397.

Yildirim, A. 2003. Instructional Planning in a Centralized School System: Lessons of A Study Among Primary School Teachers in Turkey. International Review of Education, 49(5), 525-543.

Zulhafizh, Z. (2020). Membina Aktivitas Belajar Mahasiswa di Perguruan Tinggi melalui Metode TIE (Translation, Interpretation, Extrapolation) pada Masa Pandemi Covid-19. Jurnal Kependidikan: Jurnal Hasil Penelitian dan Kajian Kepustakaan di Bidang Pendidikan, Pengajaran dan Pembelajaran, 6(3), 502-511.

Zulhafizh, Z. (2021). Peran dan Mutu Pelaksanaan Pembelajaran oleh Guru di Satuan Pendidikan Tingkat Atas. Jurnal Kependidikan: Jurnal Hasil Penelitian dan Kajian Kepustakaan di Bidang Pendidikan, Pengajaran dan Pembelajaran, 7(2), 328-339.

Zuriah, N., Sunaryo, H., \& Yusuf, N. (2016). IbM Guru dalam Pengembangan Bahan Ajar Kreatif Inovatif Berbasis Potensi Lokal. Jurnal Dedikasi, 13, 39-49. 